\title{
Review Paper on Properties of Concrete using Granite Dust and Fly Ash as a Partial Replacement of Fine Aggregate \& Cement
}

\author{
Sanjeev Sehgal ${ }^{1}$, Pratiksha Malviya² \\ ${ }^{1}$ M.Tech. Scholar, ${ }^{2}$ Professor \\ Department of Civil Engineering, Millennium Institute of Technology \& Science, \\ Bhopal, Madhya Pradesh, India
}

\begin{abstract}
How to cite this paper: Sanjeev Sehgal | Pratiksha Malviya "Review Paper on Properties Concrete using Granite Dust and Fly Ash as a Partial Replacement of Fine Aggregate \& Cement" Published in

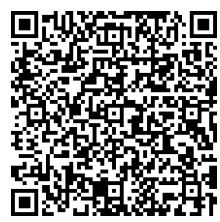
IITSRD22866 International Journal of Trend in Scientific Research and Development (ijtsrd), ISSN: 2456-6470, Volume-3 | Issue-3 , April 2019, pp.385-389, URL: http://www.ijtsrd.com/papers/ijtsrd22 866.pdf
\end{abstract}

Copyright (C) 2019

by author(s) and

International

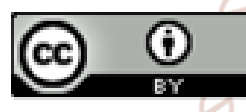

Journal of Trend in Scientific Research and Development Journal. This is an Open Access article distributed under the terms of the Creative Commons Attribution License (CC BY 4.0) (http://creativecommons.org/licenses/ by/4.0)

\section{INTRODUCTION}

Concrete is the most widely used construction material in the world it is a mixture of cement, sand, coarse aggregate and water. Cement is binding material in the cement concrete and its role is to provide strength to concrete. Cement fills up voids existing in the fine aggregate and makes the concrete impermeable. Provides strength to concrete on setting and hardening and binds the aggregate into a solid mass by virtue of its setting and hardening properties when mixed with water. Fine aggregate consist of small angular or rounded grains of silica. It is commonly used as the fine aggregate in cement concrete. It fills the voids existing in the coarse aggregate it reduces shrinkage cracking of concrete. It helps in hardening of cement by allowing the water through its voids. To form hard mass of silicates as it is believed that some chemical reaction take place between silica of sand and constituents of cement, Coarse aggregate makes solid and hard mass of concrete with cement and sand it increase the crushing strength of concrete.

\section{Materials used in Concrete}

The materials used in the projects for making concrete mixture are cement, Fine aggregate, coarse aggregate, stone dust, are detailed describe below:

Cement: Cement is by far the most important constituent of concrete, in that it forms the binding medium for the discrete ingredients. Made out of naturally occurring raw materials and sometimes blended or underground with industrial wastes. The cement used in this study was OPC 53 grades Ordinary Portland cement (OPC) conforming to IS12269-1987.
Fine aggregate: Aggregates which occupy nearly 70 to 75 percent volume of concrete are sometimes viewed as inert ingredients in more than one sense. However, it is now well recognized that physical, chemical and thermal properties of aggregates substantially influence the properties and performance of concrete. The fine aggregate (sand) used was clean dry sand was sieved in $4.75 \mathrm{~mm}$ sieve to remove all pebbles.

Course aggregate: Coarse aggregate is used for making concrete. They may be in the form of irregular broken stone or naturally occurring gravel. Material which is large to be retained on $4.75 \mathrm{~mm}$ sieve size is called coarse aggregates. Its maximum size can be up to $40 \mathrm{~mm}$.

Water: water plays an important role in the formation of concrete as it participates in a chemical reaction with cement. Due to the presence of water, the gel is formed which helps in increase of strength of concrete. Water used for mixing and curing shall be clean and free from injurious quantities of alkalies, acids, oils, salts, sugar, organic materials, vegetable growth or other substance that may be deleterious to bricks, stone, concrete or steel. Portable water is generally considered satisfactory for mixing. The $\mathrm{pH}$ value of water shall not be less than the following concentrations represent the maximum permissible values.

A. Limits of acidity: To neutralize $100 \mathrm{ml}$ sample of water, using phenolphthalein as an indicator, it should not require more than $5 \mathrm{ml}$ of 0.02 normal $\mathrm{NaOH}$. The details of the test shall be as given in IS 3025 .

B. Limits of alkalinity: To neutralize $100 \mathrm{ml}$ sample of water, using mixed indicator, it should not require more than $25 \mathrm{ml}$ of 0.02 normal $\mathrm{H}_{2} \mathrm{SO}_{4}$. The details of tests shall be as given in IS 3025 .

C. Percentage of solids: Maximum permissible limits of solids when tested in accordance with IS 3025 shall be as under:

The physical and chemical properties of groundwater shall be tested along with soil investigation and if the water is not found conforming to the requirements of IS $456-2000$, the tender documents shall clearly specify that the contractor has to arrange good quality water construction indicating the source. 
International Journal of Trend in Scientific Research and Development (IJTSRD) @ www.ijtsrd.com eISSN: 2456-6470

A. Water found satisfactory for mixing is also suitable for curing. However, water used for curing shall not produce any objectionable stain or unsightly deposit on the surface.

B. Sea water shall not be used for mixing or curing.

C. Water from each source shall be tested before the commencement of the work and thereafter once in every three months till the completion of the work. In the case of ground water, testing shall also be done for a different point of drawdown. Water from each source shall be got tested during the dry season before monsoon and again after the monsoon.

\section{Fly Ash}

Fly ash remains in one of the deposits produced in the burning of coal, Fly cinder is for the most part caught shape the fireplaces of coal-terminated power plants and is one of two kinds of slag that together are known as coal powder; the other, base fiery remains, is expelled from the base of coal heater. Contingent on the source and cosmetics of the coal being scorched, the parts of guileful cinder shift extensively, however all fly fiery debris incorporates considerable measures of silicon dioxide and calcium oxide. Fly powder is named Class $\mathrm{F}$ Class $\mathrm{C}$ composes. The supplanting of Portland bond with fly fiery remains is considered to decrease the ozone harming substance impression of concrete as the creation of one ton of Portland concrete delivers around one ton of carbon dioxide when contrasted with zero carbon dioxide delivered utilizing existing fly slag. It has been utilized effectively to supplant Portland bond without antagonistically influencing the quality and solidness of cement. A few lab and field examinations including concrete containing fly fiery remains had answered to display astounding mechanical and sturdiness properties. In any case, the pozzolanic response of fly fiery debris being a moderate procedure, its commitment towards the quality advancement happens just at later ages. Because of circular state of lay fiery remains particles, it can likewise expand workability of bond while lessening water request of the solid.

\section{Granite Powder:}

Granite powder is obtained from the crusher units in the form of finer fraction. The highest compressive strength was achieved in samples containing $40 \%$ granite powder. This is a physical mechanism owing to its spherical shape and very small in size, granite powder disperses easily in presence of super plasticizer and fills the voids between the quarry sand, resulting in a well packed concrete mix.

Granite powder can be used as filler as it helps to reduce the total voids content in concrete. Granite powder and quarry rock dust improve pozzolanic reaction. The quarry rock dust and granite powder can be used as $100 \%$ substitutes for natural sand in concrete. The compressive, split tensile and durability studies of concrete made of quarry rock dust nearly $15 \%$ more than the conventional concrete. The concrete resistance to sulphate attack was enhanced greatly.

\section{Literature Survey}

Bashar Taha and Ghassan Nounu. 2009 have studied that the potential use of waste recycled glass in concrete as recycled glass sand and pozzolanic glass powder was examined. No major difference was found in compressive strength of concrete with the presence of recycled glass sand replacement. While, the compressive strength of concrete reduced by 16 and $10.6 \%$ at 28 and 364 days respectively when $20 \%$ of Portland cement was replaced by pozzolanic glass powder. The potential expansion of concrete due to alkali-silica reaction was monitored according to the procedure of British Standard BS 812 part 123:1999. The use of recycled glass sand replacement in concrete possesses high-risk o alkali-silica reaction expansion. Therefore cracks were observed when recycled glass sand was used as sand replacement in concrete without any precautions to minimize the risk of alkali-silica reaction such as: ground granulated blast furnace slag, Metakaolin, and lithium nitrate. The expansion associated with alkali-silica reaction was significantly reduced when the alkali-silica reaction suppressor was used in concrete.

Felix F. Udoeyo and Abdul Hyee. 2009 have studied that the compressive, split tensile and flexure strengths of concrete containing cement kiln dust as a replacement for ordinary Portland cement. The replacement levels considered for the study were 20, 40, 60 and 80\%. Plain concrete with cement kiln dust was also produced for reference purposes. From the results fo the work, it was observed that there was generally a decrease in strength of cement kiln dust concrete compared to the reference concrete. However, it was noted that the percentage reduction in strength was minimal when up to $20 \%$ of OPC was replaced by cement kiln dust in the concrete. The results of the study also confirmed the previous report that the setting time of cement paste increases when cement kiln dust is used as a replacement for cement.

Tahir Celik, Khaled Marar 2010 have studied that the crushed stone dust content in aggregate on properties of fresh and hardened concrete are not known very well. An experimental study was undertaken to find out the effects of various proportions of dust content on properties of fresh concrete and hardened concrete.

Radhikesh P. Nanda, Amiya K. Das, Moharana N. C. 2010 Have examined parametric trial for creating clearing squares utilizing crusher tidy is exhibited. A portion of the physical and mechanical properties of clearing obstructs with fine total supplanted by different level of crusher tidy are researched. The test outcome demonstrates that the substitution fine total by crusher clean up to half by weight negligibly affects the diminishment of any physical and mechanical properties while there is a sparing of $56 \%$ of cash. This additionally decreases the weight of dumping crusher tidy on earth, which diminishes ecological contamination

H. M. A. Mahzuz, A. A. M. Ahmad and M. A. Yusuf. 2011 have considered that stone tidy delivered from stone pounding zones shows up as an issue for compelling transfer. Sand is basic fine total utilized as a part of development fill in as fine total. In this investigation the principle concern is to locate an option of sand. Substitution of ordinary sand by stone powder will serve both strong waste minimization and waste recuperation. Cement of stone powder and block chip increased around 10\% higher quality than that of the solid typical sand and stone chip concrete. The most astounding compressive quality of mortar found from stone powder, which is $33.02 \mathrm{MPa}$, demonstrates that better mortar can be set up by the stone 
powder. The compressive quality of cement from stone powder demonstrates $14.76 \%$ higher incentive than that of the solid made of typical sand. Then again, concrete from block chip and stone powder deliver higher compressive incentive from that of block chip and typical sand concrete.

Divakar Y. , et al. , (2012) Highlighted the compressive strength has increased by $22 \%$ with the use of $35 \%$ replacement of fine aggregates with granite fines. With increase of granite fines up to $50 \%$ increasing compressive strength will limit to $4 \%$ only. The split tensile strength remains same for $0 \%, 25 \%$ and $35 \%$. For $5 \%$ replacement there is an increase of $2.4 \%$ of strength and for $15 \%$ replacement there is a reduction of tensile Strength by $8 \%$. However we can conclude that with the replacement of $35 \%$ granite fines the test results shows no decrease in strength compared with the conventional mix using fully sand as fine aggregates. The flexural strength of prism of $10 \mathrm{~cm} \times 10 \mathrm{~cm} \mathrm{x}$ $50 \mathrm{~cm}$ without reinforcement, we can conclude that, there is $5.41 \%$ increase in flexural strength with $5 \%$ replacement, and there is a small decrease up to $5 \%$ in flexural strength at $15 \%, 25 \%$ and $35 \%$ replacement with granite fines and further reduction in strength (i.e. $6 \%$ ) at $50 \%$ replacement of granite fines in comparison with test results of nominal concrete mix of 1:1.5:3 (M-20) without granite fines. However there is no much change in flexural strength test conducted of all the variations.

Joseph 0. et al. , (2012) concluded that the flexural and tensile strength properties were found to compare closely with those for normal concrete. Hence, concrete with mixtures of lateritic sand and quarry dust can be used for structural construction provided the proportion of lateritic sand content is kept below 50\%. Both flexural and tensile strengths were found to increase with increase in laterite content. Further work is required to get data for long-term deformation characteristics and other structural properties of the experimental concrete. These include: shear strength, durability, resistance to impact, creep, etc. Also, it may be necessary to investigate the optimum contents of lateritic sand and quarry dust in relation to the structural properties of the concrete. These will assist engineers, builders and designers when using the materials for construction works. Felixkala. T et al. , (2012) concluded that the study on the performance concrete made with granite powder as fine aggregate and partial replacement of cement with $7.5 \%$ Silica fume, $10 \%$ fly ash, $10 \%$ slag and $1 \%$ super plasticiser subjected to water curing is conducted for finding the characteristic mechanical properties such as compressive strength, split tensile strength, modulus of elasticity, plastic and drying shrinkage strains of concrete mixtures at $26^{\circ} \mathrm{C}$ $\left( \pm 2^{\mathrm{O}} \mathrm{C}\right)$ and $38^{\circ} \mathrm{C}\left( \pm 2^{\mathrm{O}} \mathrm{C}\right)$ for $1,7,14,28,56$ and 90 days of curing for 0.40 water-cement ratio. The test results show clearly that granite powder as a partial sand replacement has beneficial effects of the mechanical properties of high performance concrete. Of all the 6 mixtures considered, concrete with $25 \%$ of granite powder (GP25) was found to be superior to other mixtures as well as GP0 and NA100 for all operating conditions. Therefore the conclusions are made based on a comparison of GP25 with the conventional concrete with $0 \%$ of granite powder, GP0. Mechanical properties such as compressive strength, split tensile strength and modulus of elasticity, particularly in all the ages at both curing temperature of $26^{\circ} \mathrm{C}$ and $38^{\circ} \mathrm{C}$ higher than that of the reference mix, GP0. There was an increase in strength as the days of curing increases and decreases as the curing temperature increases. The plastic shrinkage strain was primarily affected by the type of admixtures or other cementitious material used. Plastic shrinkage strain in the GP25 specimens was more than that in the CC specimens. The plastic shrinkage strain in the GP25 specimens was on an average $60 \%$ more than that in the CC specimens. The drying shrinkage strain in the granite powder concrete specimens was more than those in the CC specimens.

Manasseh Joel (2013) explained that the use of crushed granitefine to partially replace Makurdi river sand in concrete production will require a higher water to cement ratio, when compared with values obtained with the use of only Makurdi river sand. Peak compressive strength and indirect tensile strength values of $40.70 \mathrm{~N} / \mathrm{mm} 2$ and $2.30 \mathrm{~N} / \mathrm{mm}^{2}$ respectively were obtained when Makurdi river sand was replaced with 20\% CGF in concrete production. Peak compressive strength and indirect tensile strength values of $33.07 \mathrm{~N} / \mathrm{mm} 2$ and $2.04 \mathrm{~N} / \mathrm{mm} 2$ respectively were obtained when crushed granite fine was replaced with $20 \%$ river sand as fine aggregate in the production of concrete. The use of only CGF to completely replace river sand is recommended where CGF is available and economic analysis is in favor of its usage.

G. Balamurugan Dr. P. Perumal 2013 This test think about presents the variety in the quality of solid when supplanting sand by quarry dust from $0 \%$ to $100 \%$ in ventures of $10 \%$. M20 and M25 evaluations of cement are taken for the investigation keeping a steady droop of $60 \mathrm{~mm}$. The compressive quality of solid 3D squares at age of 7 and 28 days is gotten at room temperature. Split rigidity and flexural quality of cement are found at 28 years old days. From the test outcomes it is discovered that the greatest compressive quality, rigidity and flexural quality are acquired just at half substitution. This outcome gives clear picture that quarry residue can be used in solid blends as a decent substitute for characteristic stream sand at half supplanting with extra quality than control concrete

M. Vijayalakshmi, A. S. S. Sekar. , G. Ganesh Prabhu. 2013 have examined that the rock stone handling industry produces huge amounts of non-biodegradable fine powder squanders and usage of that risky waste in solid generation will prompt green condition and reasonable solid innovation. Solid blend were set up by $0 \%, 5 \%, 10 \%, 15 \%$, $20 \%$ and $25 \%$ of fine total substituted by stone powder squander. The acquired test outcomes were demonstrated that the substitution of regular sand by rock powder squander up to $15 \%$ of any definition is good for the solid making without antagonistically influencing the quality and strength criteria. Notwithstanding it is prescribed that the rock powder waste ought to be subjected to a compound blanching process preceding mix in the solid to build the sulfate protection.

V. L. Bonavetti, E. F. Irassar. 2015 have studied that stone dust up to $20 \%$ as replacement for equal weight of sand the result showed an improvement in strength of mortars containing stone dust at early ages, while water demand and porosity increases with increasing dust content. This gain of strength is attributable to the acceleration of the cement 
hydration at early ages due to effect of the stone dust. At later ages no detrimental effects were observed.

Brajesh Kumar Suman, Vikas Sribastava 2015 Have considered that the stone clean is such an elective material which can be enough being used as a piece of advancement as midway substitution of ordinary sand. In this examination, a test program was finished to consider the sensibility and potential usage of stone spotless as inadequate substitution of fine aggregate in cement. To accomplish this model were tossed for different substitution level at a between time of \% to choose functionality and compressive nature of concrete at different level of fine aggregate with stone clean. Results shows that perfect supplanting with stone clean is $60 \%$ in light of compressive quality.

M. Usha Rani J. Martina Jenifer 2016 concentrated that Solid is the most material being utilized in framework advancement all through the world. Sand is a prime material utilized for arrangement of mortar and cement and which assumes a noteworthy job in blend structure. Characteristic or Waterway sand are weathered and exhausted particles of rocks and are of different evaluations or sizes relying on the measure of wearing. Presently a-days decent sand isn't promptly accessible, it is transported from a long separation. Those assets are likewise debilitating quickly. The nonaccessibility or lack of waterway sand will influence the development business, consequently there is a need to locate the new elective material to supplant the stream sand, with the end goal that abundance waterway disintegration and damage to condition is counteracted.

Divakar. Y , Manjunath. S and Dr. M. U. Aswath 2016 Stone fines which are the side-effect delivered in stone plants while slicing enormous stone rocks to the coveted shapes. While cutting the stone shakes, the powder created is conveyed by the water and this water is put away in tanks. After dissipation of water the rock dust remained is transported and arranged on the terrains.

P. P. Shanbhag, V. G. Patwari 2017 The present study is aimed at utilizing Waste marble powder and quarry sand as partial replacement of cement and fine aggregate in concrete and comparing it with conventional concrete. This experimental investigation is carried out in three phases in 1st phase M20 grade of concrete is produced by replacing cement with $0 \%, 5 \%, 10 \% \& 15 \%$ of Marble Powder. In 2nd phase concrete is produced by replacing sand with $0 \%, 30 \%$, $40 \% \& 50 \%$ of quarry sand and in 3 rd phase concrete is produced by replacing cement and fine aggregate in the percentage of $0 \%, 5 \%, 10 \% \& 15 \%$ of Marble Powder and $0 \%, 30 \%, 40 \%$ \& $50 \%$ of quarry dust respectively. It is found that the studies of concrete made of waste marble powder and quarry sand increases at 10\% and $40 \%$ respectively. Therefore the quarry dust and waste marble powder should be used in construction works, then the cost of construction would be saved significantly and the natural resources would be used efficiently.

Khushal Chandra Kesharwani 2017 Fly fiery remains use in concrete as incomplete substitution of bond is picking up significance step by step. Mechanical upgrades in warm power plant tasks and additionally gathering frameworks of fly fiery remains enhanced the nature of fly cinder. To examine the utilization of fly slag in solid, bond is supplanted mostly by fly fiery debris in cement. In this exploratory work solid blend arranged with substitution of fly powder by $0 \%$, $25 \%$, half, $75 \%$ and $100 \%$. Impact of fly fiery remains on functionality, setting time, compressive quality and water content are considered. To examine the effect of halfway substitution of bond by fly cinder on the properties of solid, tests were led on various cement blends.

This paper on audit on exploratory examination on selfcompacting concrete by utilizing mineral added substance, for example, Fly fiery debris, Small scale silica and Metakaolin. Self-Compacting concrete is a solid that show the high stream capacity and maintain a strategic distance from the isolation and dying. The modern waste, for example, fly fiery remains use in this undertaking as an incomplete substitution of bond to create concrete.

Chandra Rathor 2018 Self-compacting concrete is one of "the most progressive improvements" in solid research; this solid can stream and to fill the most restacked spots of the frame work without vibration. There are a few strategies for testing its properties in the new express: the most regularly utilized are Slump-flow test, L-box, U-box and V-funnel. This work presents properties of self-compacting concrete, blended with various kind's added substances: fly powder, miniaturized scale silica, metakaolin. So we included admixture air conditioning hypercrete and air conditioning viscocrete around $0.5 \%$ and $0.2 \%$ of aggregate cementitious content in each blend from that point. The compressive quality conveyed in the compressive testing machine. The increments of fly slag were $20 \%, 25 \%, 30 \%$ and $35 \%$ of cement. It was seen that expansion the level of fly powder brought about the decline of compressive strength.

\section{Problem Identification}

$>$ The Eco-Friendly and reliable development for construction consists the use of non-conventional and different waste materials and recycling of waste material for reducing emissions in environments and decreasing the use of natural resources.

Scarcity of natural sand and cement necessitates alternate substitute materials

$>$ Fly ash and Granite Powder is generated in large quantity as a byproduct of industrial waste.

\section{Objectives}

The objectives of the research are outlined below:

$>$ To find out alternative materials as partial replacement of cement and fine aggregate (sand).

$>$ To check the workability of the concrete by adding fly ash and granite powder.

\section{CONCLUSION}

$>$ The Granite powder is to be used as partial replacement of the natural sand.

$>$ The use of Granite powder in concrete is beneficial in different manner such as environmental aspects, nonavailability of good quality of fine aggregate or rarely availability, strength quality etc.

\section{REFERENCES}

[1] P. Jaishankar and Vayugundla chenchu Eswara Rao, “ Experimental study on the Strength of Concrete by using Metakaolin and M-sand". International Journal of ChemTech Research, Vol.9, No.05 pp 446-452, 2016.

[2] Premalatha and Sudarrajan, "Mechanical Strength 
International Journal of Trend in Scientific Research and Development (IJTSRD) @ www.ijtsrd.com eISSN: 2456-6470

Properties, of High Strength Fibrous Added to Concrete", ACI Material Journal,2007.

[3] Sudheer jirobe, Brijbushan S, Maneeth D. “Experimental investigation on strength and durability properties of hybrid fiber reinforced concrete" International Research Journal of Engineering and Technology (IRJET) Volume: 02 Issue: 05, Aug-2015. PP 891- 896.

[4] T. Shanmugapriya and Dr. R. N. Uma, "Strength and Durability Studies on High Performance Concrete With Manufactured Sand as Fine Aggregate". International
Journal of Applied Engineering Research, Vol. 10, No. 2 pp 1919-1924, 2015.

[5] V. S. Vairagade, KS Kene, T.R Patil “Comparative Study of Steel Fiber Reinforced Over Control Concrete", International Journal of Scientific and Technology, 2012.

[6] Y. Mohammadi, S. P. Singh and S. K Kaushik, "Properties of Steel Fibrous Concrete Containing Mixed Fibers in Fresh and Hardened State", Construction and Building Materials, May 2008, Vol. 22(5);956-965. 